\title{
Competency-Based Education: The Value for Students, Academic Institutions, and Organizations
}

\author{
Sunil Ramlall ${ }^{1} \&$ Dhanmati Ramlall $^{2}$ \\ ${ }^{1}$ Academic Program Chair, Western Governors University, USA \\ ${ }^{2}$ Accounting Faculty at Century College, Minnesota State, USA \\ Correspondence: Dr. Sunil Ramlall is currently Program Chair in the College of Business at Western Governors \\ University, USA. Tel: 1-651-210-2761. E-mail: sramlall001@gmail.com
}

Received: July 17, 2020 Accepted: July 24, 2020 Online Published: August 5, 2020

doi:10.5430/jbar.v9n2p1 URL: https://doi.org/10.5430/jbar.v9n2p1

\begin{abstract}
This article examines the practices around Competency-Based Education (CBE) in the U.S. by examining best practices and interviews with leaders at multiple academic institutions to understand strategies being used, identify strengths and opportunities of CBE initiatives. Furthermore, the research will also include discussions on implications for organizations using a CBE approach to training and development strategies, and how HR leaders can extrapolate from current practices in academic institutions to organizations.
\end{abstract}

Keywords: competency-based education, students, organization

\section{Introduction}

What is CBE? Educational programs that are competency-based are designed around the knowledge, skills, and professional dispositions that are necessary for success in a particular industry or field. With their high practicality for learners and employers, it's no surprise that since 2012, the number of CBE programs in the U.S. has grown from 20 to more than 500 .

Competency-based higher education highlights the competencies of individuals and often enables students to progress at their own pace. CBE programs offer working adults a convenient, self-paced way to earn a bachelor's degree (McDonald, 2018). How can we create more access to quality and affordable education in the U.S.? How can we significantly assist more students to reach their educational goals and improve their employment outcomes? How can we recognize the learning and experience the vast number of nontraditional students bring when they come to our colleges seeking a path to improved career opportunities and family-sustaining wages?

In the twenty-first century, a high-quality, affordable postsecondary education is the key to both national competitiveness and individual success (Johnstone \& oares, 2014).

The value-proposition of CBE is that learners are able to demonstrate expertise in a body of knowledge and be able to apply the knowledge and skills in the real world. This reorientation builds a bridge between academics and employers, resulting in a better understanding of the knowledge and skills that students will need to succeed in work and in life. This is assuming that degree programs, course content, and learning outcomes are developed and designed in alignment with industry trends, practices, and expectations.

Competencies are defined as a cluster of related knowledge, characteristics, attitudes and skills which have a great impact on the individual's job, have correlation with an individual's performance at work, can be evaluated by the accepted standards and are improved through training and development (Sanchez, 2010).

While institutions such as Capella, Rasmussen, Western Governors University (WGU), and numerous other highly reputable institutions are using the $\mathrm{CBE}$ method, the argument is that $\mathrm{CBE}$ is an approach that improves teaching and student learning and provides a means for helping quality and affordability co-exist in higher education.

\section{Implications for Higher Education, Industry, and Students}

Historically, organizations have sought respective degrees as a means to deciding on the qualifications of an applicant in helping to predict their performance. Do student really have to be in a semester long course comprising fifteen weeks to gain the knowledge and be able to demonstrate attainment of the knowledge to successfully 
complete a course? As we look at student retention, learners can become disengaged, bored, or less motivated in the registered course. Through work experience, individualized learning, and any given course materials, student can demonstrate their knowledge of a course content through objective assessments and performance assessments.

Affordability

- Is CBE a model that means affordability for more learners thus making higher education more accessible?

- Could a shorter time to successfully complete a degree mean less disruption to families?

- Can employers utilize a CBE model for Training and Development resulting in higher levels of productivity and be a more cost-efficient approach?

Training and development interventions in organizations can sometimes be ongoing throughout a calendar year. Are $T \& D$ leaders able to integrate a CBE perspective, enabling learners to demonstrate their expertise in a given subject matter rather than having to participate in many hours of training? The concept of CBE applies in that trainers can facilitate assessments interventions that would determine an employee's knowledge and ability to practice the concepts/materials/tools. How would this be of utility?

There is less time for employees to spend pursuing a course. Instead, the employees can choose different methods in pursuing the course, such as an individualized approach, cohort-based, or choose to do a hybrid. There is less time away from one's work. Productivity is impacted in a positive manner in that employees are developing additional expertise yet able to spend the time in their jobs.

\section{Competency-Based Education in Practice}

Students earn competency units based on demonstrated mastery of the course material through performance assessments or objective assessments. In the traditional model, the student is awarded credit hours based on "seat time" - a certain number of hours for 10 weeks per quarter or 15 weeks per semester, and a grade of D or better. At WGU, students show the competency of knowledge, skills and abilities independent of time. The validation of content mastery is perhaps a higher standard.

The course materials are structured by competencies, created through collaboration between Product Development, current businesses and employers, and Subject Matter Experts (SMEs). The competencies are then aligned with objectives for each course. Performance assessments and objective assessments are created by the Product Development and SMEs.

Students utilize a variety of learning resources, according to their needs, including but not limited to: online textbooks, quizzes, synchronous live sessions, 1:1 discussion with instructors and more. Since "time in seat" doesn't define the passing of the course, students' choice of type of learning and schedule for studying provides flexibility around other priorities. This may better support the student's understanding that his achievement at the university is in his control (Malan, 2000).

Further, this model may allow more students who have some college but no degree the ability to return to finish their education. Rising costs of tuition are putting higher education out of reach for most Americans, yet there is ever-increasing demand for complex skills in this global and dynamic economy (Burnette, 2016). In the WGU setting, students who have significant work history or knowledge in a subject, may attempt and pass assessments in shorter time periods. If the competency is shown, the units are earned (Soares, 2014).

Disaggregated Faculty Model

If passing an assessment is the standard by which progress to graduation is measured, the WGU model set out to safeguard the integrity of this process. The faculty is assigned only one of three roles:

Course Instructor: full-time employees who teach content, assist in individualized learning and study plans, and identify readiness for assessments in collaboration with students.

Program Mentor: full-time employees who orient students to learning resources and process; support student through goal setting, refer to university services; meet with students weekly or bi-weekly from beginning of program to graduation.

Evaluation/Assessment: scores objective assessments and evaluates performance assessments for content and articulation.

Capella University

At Capella University, FlexPath -its' direct assessment model - enables learners to move at their own pace, helping 
them balance the demands of going back to school with their busy lives. They set their own deadlines and have more control over the costs of their education. When other responsibilities like work and family grow, learners can hit pause on their degree completion timeline as well as on their tuition bills. The program, launched in 2013, has proven successful, as it recently celebrated a milestone of over 4,000 FlexPath graduates and growing (Senese, 2019).

Rasmussen College

The CBE format facilitates universities and colleges from the traditional semester or term hours to a focus on academic proficiency. Students bring experience and knowledge from current and previous work and other experiences for which they can establish proficiency of the course content. Put simply, students are able to demonstrate their knowledge through the respective assessments (Doherty, 2018). Rasmussen College defines CBE of academic instruction and evaluation based upon students demonstrating their mastery of a subject. This method focuses on having students "show what they know" and applying the concepts they've learned to evaluations that show they've truly grasped the subject.

Do student actually save money? At Rasmussen College, students have the option to supplement their standard CBE courses with self-directed assessments that allow them to test out of courses they may already have a handle on.

\section{What's the Value of Competency-Based Education for Students and Employers?}

The findings of this study suggest that CBE can make a valuable complement to the traditional higher education model and a functional alternative pathway to post-secondary credentials. While CBE has the potential to enhance existing models of higher education to address access, quality, and productivity challenges, it is certainly not a panacea that will save higher education and no one has claimed that it is. What competency-based education can bring is a catalyst for change and innovation that our higher education system desperately needs (Chen, 2018).

In reviewing these CBE programs and others, we found them to be flexible as their structure depends on the individual learner, the programs facilitated students to control their pacing because they are not confined by a set learning process, and student have more ownership over their learning. A major benefit is the cost and the ability to the cost of CBE programs and the opportunity for students to integrate their real-world skills and competency development. Furthermore, employers are able to partner with academic institutions to reduce the time employees spend on a course, integrate practical experiences for credits, and ensure the relevance of course information to practice in the industry.

\section{References}

Chen, F. (2018). An alternative pathway to college: A qualitative case study of an adult learner in an online competency-based education (CBE) bachelor's degree program. (79), ProQuest Information \& Learning, Retrieved from https://postu.idm.oclc.org/login?auth=prodbb\&url=http://search.ebscohost.com/login.aspx?direct=true \&db=psy $\mathrm{h} \& \mathrm{AN}=2017-54449-012 \&$ site $=$ ehost-live \&scope $=$ site Available from EBSCOhost psyh database.

Doherty, B. (2018). What Is Competency-Based Education? A Beginner's Guide for Students.

McDonald, N. A. n. a. m. w. e. (2018). A Private, Nonprofit University's Experiences Designing a Competency-Based Degree for Adult Learners. Journal of Continuing Higher Education, 66(1), 34-45. https://doi.org/10.1080/07377363.2018.1415632

Sanchez, J. (2010). University training for entrepreneurial competencies: Its impact on intention of creation. Springer Science and Business Media. https://doi.org/10.1007/s11365-010-0156-x

Senese, R. (Producer). (2019). Competency-Based Education is Growing, because It Works for Adult Learners.

Soares, S. M. J. L. (2014). Principles for Developing Competency-Based Education Programs, Change. The Magazine of Higher Learning, 46(2), 12-19. https://doi.org/10.1080/00091383.2014.896705

\section{Sunil Ramlall}

Dr. Sunil Ramlall is currently Program Chair in the College of Business at Western Governors University. Prior, Ramlall was an HR/Learning and Development Consultant for 11 years. He was also Associate Professor of Management at Cardinal Stritch University \& Hamline University, and an Assistant Professor of Management at both Minnesota State University and University of St. Thomas.

Sunil holds a Ph.D. and Master of Education in Human Resources Development from the University of 
Minnesota - Twin Cities. He also has an MBA and Human Resource Management and a BA in Business Administration from the University of Saint Thomas.

Dhanmati Ramlall

Dhanmati Padma Ramlall is an Accounting Faculty at Century College, Minnesota State where she has been teaching for more than six years. Dhanmati teaches Financial, Accounting, Managerial Accounting, and Capstone courses. Prior to teaching at Century College, Padma worked as a Senior Accountant at Minnesota State Colleges and Universities System.

Her education includes a BS in Business Administration from Metropolitan State University, an MBA in Accounting from the University of St. Thomas, and MS in Accounting from Western Governors University. She is also the author of multiple scholarly journal articles, including one on soft skills in the accounting profession.

Utilizing her education, several years of professional accounting experience, and passion for teaching, Dhanmati is able to teach the accounting concepts and the relevance to organizational outcomes.

Padma and her family reside in Rosemount, $\mathrm{MN}$ and are active in various community events. 